\title{
VITIMOLOGIA E GÊNERO NO PROCESSO PENAL BRASILEIRO
}

Luanna Tomaz de Souza ${ }^{4}$

\section{VICTIMOLOGY AND GENDER IN THE BRAZILIAN CRIMINAL PROCEDURE}

\section{Resumo}

Durante muito tempo a vítima foi ignorada no processo penal. A vitimologia surge inicialmente sob um ponto de vista positivista, mais preocupado em evidenciar a contribuição da vítima para o cometimento do crime, sendo que nas últimas décadas tomam nova direção destacando a expropriação do conflito, preocupando-se com a efetivação dos direitos e garantias da vítima. O movimento feminista, ao destacar a forma com que o Direito contribui para as desigualdades de gênero, determinando compreensões de "homem" e "mulher", e criticar a forma com que a mulher é tratada pelo sistema penal, amplia as reflexões acerca das dinâmicas processuais existentes. Conclui pela necessidade de se romper com a estrutura processual de expropriação do conflito, com a devida participação do afetados no processo de construção e reconstrução comunicativa de seus direitos. Isso garante que a decisão será construída pelo discurso argumentativo empreendido pelas partes e não pela atuação isolada do juiz.

Palavras-chave: Vitimologia. Processo penal. Mulher. Vítima.

\section{Abstract}

For a long time, the victim was ignored in the criminal proceedings. The victimology appears initially under a positivist point of view, more concerned with highlighting the contribution of the victim for the crime, and in recent decades take new direction emphasizing the expropriation of the conflict, concerned with the enforcement of rights and guarantees of victim. The

4 Bacharel em Direito (UFPA) e em Ciências Sociais(UNAMA); Mestre em Direito (UFPA); Doutoranda em Direito, Justiça e Cidadania pela Universidade de Coimbra; Professora de Direito da Universidade Federal do Pará; E-mail: Iuannatomaz@bol.com.br 
feminist movement to highlight the way that the law contributes to gender inequalities, determining understandings of "man " and "woman" and criticizing the way women are treated by the criminal justice system, enhances the reflections on the process dynamics existing. Concluded by the need to break with the procedural framework for the expropriation of the conflict with the due participation of the affected in the process of construction and reconstruction of communicative rights. This ensures that the decision will be built by the argumentative discourse undertaken by the parties acting alone and not by the judge.

Keywords: Victimology. Criminal Procedure. Women. Victim.

\section{Introdução}

A partir do momento em que o Estado avocou o direito de punir com o monopólio do jus puniendi, houve um consequente distanciamento da vítima e dos conflitos em que se encontrava inserida. Nesse momento histórico, afastá-la dessa função foi prudente e bastante necessário para fins de assegurar a imparcialidade, tão cara ao processo penal, haja vista ser a atividade estatal mais racional e menos emotiva. No entanto, não se pode olvidar que a vítima é a titular primária do bem jurídico violado pela prática delituosa e é evidente a sua intenção de ver "compensado", tanto quanto possível, o seu sofrimento.

O modelo tradicional do Processo Penal brasileiro estabelece um conflito travado entre o acusado e o Estado e gira, tão somente, em torno de assegurar à sociedade uma resposta para aquela violação ao Direito. Esse sistema ignora, todavia, o fato de que, na maior parte das vezes, na base do delito há um conflito humano com expectativa distinta da mera pretensão punitiva intentada pelo Estado. A pena imposta pelo Estado-juiz acaba assim por não guardar nenhuma relação com a pessoa efetivamente prejudicada no conflito.

A vítima não atua assim como protagonista do processo penal, já que este se volta somente à condenação do acusado, e ainda por vezes termina sofrendo com a dinâmica processual que se abstém de amenizar os transtornos decorrentes de todo o procedimento punitivo, não recebendo, 
ou recebendo precariamente, amparo por parte do Estado diante de todo o sofrimento oriundo da lesão a seu bem jurídico, como a reparação do dano, por exemplo.

O indivíduo teve um bem jurídico seu diretamente violado e se encontra extremamente fragilizado quando procura o Estado, mas é tratado como objeto de investigação e não como sujeito de direitos. A vítima sofre com maus-tratos nas Delegacias, sendo submetida a situações constrangedoras, não somente para prestar seu depoimento diante do acusado, como em toda a fase processual, pois a preocupação estatal figura em torno apenas do criminoso.

Somente na década de 1970 surgem estudos voltados a tirar a vítima de seu anonimato e inseri-la num contexto de efetivação de direitos e cidadania, principalmente com a crise do Estado Social e o advento do Estado Democrático de Direito. É nesse diapasão que a vitimologia e o movimento vitimológico passam a discutir o novo papel da vítima, o que será abordado no primeiro item deste artigo.

A crítica do movimento vitimológico é quanto à expropriação do conflito pelo Estado, que se coloca como sujeito passivo constante do delito e é compartilhada com outros movimentos, como o abolicionista penal e os movimentos feministas.

Estes últimos assumem grande preocupação com o tema, diante da percepção do processo de violência institucional sofrida pelas mulheres quando vítimas de violência, deparando-se com o descrédito, a humilhação e a falta de amparo do Estado, o que é retratado no segundo item deste artigo. Sua contribuição é significativa para identificar a forma como o Direito Penal tem sido determinante para estruturação das desigualdades de gênero.

No último item, aborda-se uma importante base filosófica crítica a este modelo de resolução de conflitos, com autores como Habermas e Fazzalari, voltados a uma compreensão procedimentalista e discursiva do Direito, em que os cidadãos são considerados destinatários, mas também autores das normas e partícipes do processo. No paradigma do Estado democrático de direito, opera-se uma mudança com a participação dos afetados no processo de construção e reconstrução comunicativa de seus direitos. 
O objetivo deste artigo é assim pensar em que medida as contribuições trazidas pelos movimentos feministas e vitimológicos são importantes para repensar a dinâmica processual penal brasileira sob uma nova justificação filosófica e sob uma nova base procedimental.

\section{Vítima, vitimologia e sobrevitimização}

Durante longo período histórico a vítima ficou à margem da preocupação dos estudos na área do direito penal e processual penal, sendo abandonada em detrimento da preocupação com o agressor. Tanto a Escola Clássica de Becaria e Fuerbach, como a Escola Positiva de Lombroso, Ferri e Garofalo, estavam centradas na tríade delito-delinquente-pena. Nenhuma dessas correntes levou em consideração o outro componente da relação jurídico-penal, que é a vítima.

Lúcia Zedner (1997) aponta que o termo "vitimologia" foi utilizado por primeiro pelo psiquiatra americano Frederick Wertham, mas ganhou notoriedade com o trabalho de Hans von Hentig "The Criminal an his Victim", de 1948. Neste trabalho o autor propõe uma abordagem dinâmica, interacionista, desafiando a concepção de vítima como ator passivo, destacando que algumas características das vítimas poderiam precipitar os fatos ou condutas delituosas, e a necessidade de analisar as relações existentes entre esta e o agressor.

Outra obra importante foi publicada no ano de 1956, pelo advogado israelita Benjamin Mendelsohn, nela constando um artigo sobre "Vitimologia", que era parte de uma obra mais ampla (Horixons nouveaux bio-psychosociaux. La victimiologie). Mendelsohn foi o primeiro a utilizar a expressão vitimologia, hoje consagrada na doutrina.

O surgimento da vitimologia deu-se com a preocupação tanto da criminologia moderna como de um movimento autônomo capitaneado por Mendelsohn. Entre os autonomistas encontramos Manzanera e, no Brasil, Scarance Fernandes, que defendem a ampliação da vitimologia sem o necessário atrelamento à Criminologia.

O estudo da vítima no processo penal tomou novos rumos após a dé- 
cada de 1970, principalmente com a crise do Estado Social e o advento do Estado Democrático de Direito. É nesse diapasão que a vitimologia e o movimento vitimológico passam a discutir o novo papel da vítima, colocando-a no foco de atenções.

Apesar de a vitimologia defender um conceito de vítima mais amplo do que o da vítima de delito, é inegável a importância da vitimologia criminológica para estruturação da disciplina. Os primeiros estudos sobre a vítima levam em conta a criminologia, principalmente aquela de caráter positivista, com enfoque para os estudos das causas biológicas, antropológicas e sociais do comportamento delinquente. Desse modo, surge uma grande preocupação em definir causas biológicas, sociais ou antropológicas do comportamento vitimal, o que pode ser observado em inúmeras classificações, perfis, ou tipologias que a vítima recebeu.

Esses primeiros estudos de forte conotação positivista foram importantes para justificar inicialmente a existência da vitimologia, mas atualmente perderam sua importância, haja vista que essa ciência não se presta a justificar o comportamento do agente, mas a buscar soluções que evitem ou amenizem a vitimização, já que o crime até certo ponto faz parte da sociedade e não será facilmente extinto, conforme defendia Durkheim.

A vitimologia vai assim muito além do estudo da influência da vítima na ocorrência do delito, pois estuda os vários momentos do crime, desde o fato até as suas consequências. Abrange o estudo científico da extensão, natureza e causas da vitimização criminal, suas consequências para as pessoas envolvidas e as reações àquela pela sociedade, em particular pela polícia e pelo sistema de justiça criminal. Hoje um campo de estudo orientado para a ação ou formulação de políticas públicas, sendo que as violações a direitos humanos são consideradas questão central de estudo.

Garcia-Pablos de Molina (1992) faz uma importante distinção entre três fases pelas quais as vítimas de atos ilícitos, especialmente de delitos, passaram: a de protagonismo, de neutralização, e de redescobrimento. A primeira correspondeu ao período da vingança privada, em que os danos produzidos sobre uma pessoa ou seus bens eram reparados ou punidos pela própria pessoa. A resposta ao delito assume critérios vingativos e punitivos, quase nunca reparatórios. 
A justiça privada surge como uma primeira tentativa de controlar a revindicta, evitando que a paz social fosse constantemente abalada ou que acusados que não tivessem sua culpa comprovada por ela fossem atingidos. Além disso, procurava-se estabelecer a proporcionalidade entre a agressão do autor e a retribuição da vítima.

Na segunda fase, que vai desde o Direito Romano até o século XX, entende-se que a resposta ao crime deve ser imparcial, desapaixonada, despersonalizando a rivalidade. A linguagem simbólica e o formalismo do direito transformam vítimas concretas em abstrações, tirando seu papel central na resolução do conflito.

Progressivamente, a vingança privada e a justiça privada foram dando lugar à justiça pública. A noção de proibição da justiça pelas próprias mãos que teve como ponto de partida a expropriação do conflito pelo Estado. A vítima foi sendo neutralizada passando a ser mera informadora do delito. Mais uma vez a reparação do dano não tem o foco das atenções.

O redescobrimento da vítima é um fenômeno posterior à Segunda Guerra Mundial, sendo uma resposta ética e social ao fenômeno da macrovitimização, que atingiu especialmente judeus, ciganos, homossexuais, e outros grupos vulneráveis. Também ganha relevo, na década de 1970, com o movimento feminista, e, no âmbito do Direito Penal, com o movimento abolicionista.

A importância do abolicionismo é inegável, sendo suas críticas acerca da expropriação do conflito pelo Estado paulatinamente acatadas. Os argumentos abolicionistas localizam na despersonalização do conflito uma das principais críticas ao Direito Penal acreditando que este deva passar pelos seus protagonistas. Nesse redescobrimento não se persegue nem retorno à vingança privada, nem a quebra das garantias para os criminosos, mas a efetivação dos direitos da vítima.

A questão da despersonalização do conflito deu foco aos novos estudos da vitimologia relacionados com o processo penal, estimulando a criação de meios alternativos de resolução de litígios (combatendo-se os estereótipos entre vítima e agressor) e com a preocupação em evitar a sobrevitimização, quando o processo termina atingindo aquele a quem devia proteger: a vítima. Nesse sentido, busca-se a efetivação do direito à informação, à 
participação e à proteção nas bases de um Estado Democrático de Direito e na perspectiva do direito pluralista e participativo.

Segundo Barros (2008), a vítima de hoje, contudo, não é a mesma de outrora. A ela foram agregados os atributos que integram a dignidade da pessoa humana e mais o contexto social que o do Estado Democrático de Direito, por isso até evita-se a utilização do termo redescobrimento.

Um dos primeiros pontos a se determinar é a própria expressão "vítima". O conceito etimológico de vítima tem um sentido religioso e se refere ao animal dado em sacrifício como agradecimento aos deuses pela vitória alcançada. Um conceito jurídico amplo de vítima abrange aqueles que sofrem algum tipo de ofensa a direitos fundamentais, do qual emergiria um dano ou lesão. Conceito que vai para além do Direito Penal tendo alcance multidisciplinar.

A declaração da ONU, denominada Declaração dos Princípios Básicos de Justiça para a Vítima de Delitos e Abuso de Poder, ateve-se em dois tipos de vítimas: as vítimas de delito e as vítimas de abuso de poder, compreendendo danos não reconhecidos pelo legislador nacional como delito.

1 - Entendem-se por "vítimas" as pessoas que, individual ou coletivamente, tenham sofrido um prejuízo, nomeadamente um atentado à sua integridade física ou mental, um sofrimento de ordem moral, uma perda material, ou um grave atentado aos seus direitos fundamentais, como conseqüência de atos ou de omissões violadores das leis penais em vigor num Estado membro, incluindo as que proíbem o abuso de poder.

2 - Uma pessoa pode ser considerada como "vítima", no quadro da presente Declaração, quer o autor seja ou não identificado, preso, processado ou declarado culpado, e quaisquer que sejam os laços de parentesco deste com a vítima. O termo "vítima" inclui também, conforme o caso, a família próxima ou as pessoas a cargo da vítima direta e as pessoas que tenham sofrido um prejuízo ao intervirem para prestar assistência às vítimas em situação de carência ou para impedir a vitimização.

Trata-se de um conceito de vítima exclusivo para o campo jurídico-penal. Inclui como fator vitimizador somente a conduta tipificada como ilícito penal, contudo, possui um caráter amplo ao englobar para além da pessoa diretamente atingida, seus familiares e dependentes e outros que possam ter sofrido dano ao auxiliar a vítima. 
A doutrina tradicionalmente distingue entre a vítima, sujeito passivo do crime, e o prejudicado. Quanto ao sujeito passivo, em regra é feita uma divisão entre sujeito passivo constante, o Estado, e eventual, a vítima. Contudo, esta divisão tem provocado críticas, em primeiro lugar pela definição do ilícito como ofensa a um bem jurídico protegido ou a um interesse jurídico, bem como a consequente definição de que todo ilícito penal necessariamente atinge o Estado.

Para Fernandes (1995) essa distinção é relevante em virtude da adoção de um modelo acusatório, no qual o Ministério Público é legitimado ativo da relação jurídica processual para o oferecimento da denúncia. Barros (2008) contrapõe-se, afirmando que a legitimação do Ministério Público não advém da expropriação do conflito, mas relaciona-se ao direito fundamental da tutela jurisdicional. Quando aquele está legitimado para iniciar o processo penal, o faz tendo em vista a definição em abstrato das normas jurídicas garantidoras da tutela jurisdicional, que conferem à referida instituição legitimidade para agir em juízo no âmbito das normas penais.

Também cabe observar que não obstante a inclusão dos familiares e dependentes como vítimas do delito, esses somente possuem legitimidade para atuar no processo quando da ausência ou morte da vítima. Diferentemente do sujeito passivo do crime, tais vítimas devem ser deduzidas da norma processual penal.

Há também a figura do prejudicado, em regra analisada a partir do direito à reparação do dano, ou seja, o prejudicado é aquele que sofreu danos patrimoniais em virtude do delito. Considera-se vítima o sujeito passivo, principal ou secundário. O prejudicado só será vítima quando ostente também a qualidade de sujeito passivo. Para Barros (2008), não há grande necessidade de distinção destes conceitos, pois a solução do conflito deve atingi-lo em toda sua amplitude, integralmente, para garantir a participação de todos os afetados, como é próprio de um direito pluralista e democrático.

Cabe neste momento refletir também acerca de uma das noções essenciais do conceito de vítima que leva em consideração o ilícito penal como violação de um bem jurídico protegido ou de um interesse tutelado. As definições da dogmática penal que atrelam o cometimento do ilícito à existência de um bem jurídico protegido ou um interesse tutelado têm sido 
criticadas inclusive por autores como Habermas e Gunther, pois tais conceitos possuem uma carga valorativa, axiologizante ${ }^{5}$, que diverge da teoria discursiva do direito, e, portanto, não são considerados adequados ao paradigma do Estado Democrático de Direito. Uma importante observação a ser feita é que relacionar a aplicação do Direito a valores pode privilegiar uma determinada concepção de vida boa que não pode ser considerada como padrão num Estado Democrático de Direito.

A teoria da relação jurídica erigida por Savigny ${ }^{6}$ utiliza conceitos axiológicos como bem jurídico protegido ou interesse jurídico. Define direito subjetivo como poder de alguém sobre a conduta de outrem e a relação jurídica, como vínculo normativo em que um pode exigir de outrem uma determinada conduta, como nas obrigações contratuais, em que a todo direito corresponde um dever. Esta definição possui forte influência da filosofia kantiana, a qual compreende o Direito como um caso especial da Moral.

Esta teoria sofreu diversas críticas. Chamon Júnior (2003) faz uma crítica a partir da teoria das situações jurídicas, interpretadas à luz da teoria discursiva do direito. $\mathrm{O}$ autor considera define as situações jurídicas como situações definidas pelo direito com base no juízo de adequabilidade normativo aplicado às normas prima facie, efetivado a partir da reconstrução do caso concreto. Superando a leitura moral do Direito, percebemos que direitos e deveres não precisam estar essencialmente correlacionados. Há ilícitos como "omissão de notificação de doença", onde há a infração de dever sem um direito violado. Ou, como no caso do Estado de necessidade, há um direito violado, sem a infração de um dever correspondente.

A compreensão do papel da vítima deve ser analisada justamente a partir da existência ou não de um direito violado e de um possível direito a indenização. Isto porque o direito violado não pode ter como titular sempre o Estado, como na compreensão relacionista, que o entende como sujeito passivo constante.

Não se pode entender que em todo e qualquer delito o Estado ou a

5 São feitas críticas inclusive à teoria de Alexy, que, ao definir princípios como mandatos de otimização, aproxima esses a valores, ou seja, confunde o que é devido com o que é bom.

6 Teoria da relação jurídica processual, construída no final do século XIX, à época em que a doutrina se empenhava em evidenciar a autonomia do direito processual, ainda é adotada pela imensa maioria dos processualistas, brasileiros e estrangeiros, com influência europeia. 
sociedade devem ser retratados como vítima, afinal, se levarmos a sério a distinção entre discurso de justificação e aplicação ${ }^{7}$, de Günther ${ }^{8}$, somente se pode falar em violação de um direito do Estado quando haja tal direito efetivamente, e não quando se ferem valores de comunidade. Perquirir se há direito violado em determinada situação somente é possível no discurso da aplicação, sopesando os argumentos jurídicos, definidos a partir da norma adequada, no caso concreto. A verdadeira vítima somente pode ser definida no caso em concreto, verificando-se que o descumprimento de um dever gerou um direito violado, podendo tratar-se de crime sem vítima.

Alguns têm pugnado pela existência de vítimas difusas, na violação de direitos difusos, como o meio ambiente. Na realidade, a classificação de vítima difusa não parece correta, já que o direito violado se define em concreto. Assim, a partir do caso em concreto, será possível determinar os indivíduos, ou grupo de indivíduos, afetados em razão da violação de um direito.

Outro conceito que ganha relevo nos estudos vitimológicos é o de vitimização que examina tanto a propensão para ser vítima quanto os vários mecanismos de produção de danos diretos e indiretos sobre a vítima e pode ser analisado sob três importantes aspectos: vitimização primária, vitimização secundária e vitimização terciária.

A vitimização primária ocorre com o cometimento do delito. A vitimologia inicialmente preocupava-se com a vitimização primária, a partir de uma visão positivista acerca da realização da conduta delitiva.

A vulnerabilidade da vítima está diretamente relacionada ao processo de vitimização e decorre de diversos fatores (de ordem física, psicológica, econômica e outras), o que faz com que o risco de vitimização seja diferente para cada pessoa e delito. Nesse sentido, o exame dos recursos sociais efetivos da vítima também deve ser levado em conta.

A vitimização secundária, também denominada sobrevitimização, é gerada pela indevida ou irregular atuação dos órgãos de controle social, incluindo o aparato policial e judicial, um desvio de finalidade, tendo em vista que estas instâncias deveriam evitar a vitimização. Atualmente tem se

7 Klaus Günther acredita que o discurso jurídico comporta dois níveis discursivos: discursos de justificação e de aplicação. Segundo ele, a justificação de normas e a aplicação de normas, sejam elas regras ou princípios, têm objetivos distintos e são orientadas por princípios norteadores específicos.

8 GÜNTHER,Klaus. Thesense ofappropriateness. Albany:StateUniversityofNewYorkPress. 1993.p.67. 
atribuído muito mais atenção a estes estudos.

Diante do alto número de subnotificações, que faz com que a polícia só investigue uma pequena parcela dos crimes que realmente acontecem, Dias e Andrade (1997) chegam à conclusão de que a polícia não investiga quando a vítima se opõe fortemente, nem quando o investigado é muito poderoso. Daí a importância da contribuição da vítima desde a fase policial e dos estudos acerca dos percalços para o registro da ocorrência.

Por outro lado, também se verifica a construção de um perfil de vítima ideal. Esta deve ser aquela que pode ser uma boa testemunha que contribui com todo o processo, sem contradições, e que cumpre seu papel social de "boa mulher" ou de "bom homem".

A Declaração sobre os princípios fundamentais de justiça para as vítimas de delitos e do abuso de poder, da ONU, deu uma direção importante acerca dos direitos da vítima, que envolve: garantia de acesso à justiça e tratamento justo; tratamento com compaixão e respeito; informação sobre seu papel e alcance; assistência apropriada (legal, médica, psicológica); ressarcimento dos danos; informação sobre a tramitação processual. Dentre os direitos das vítimas temos basicamente: tratamento justo e respeito à sua dignidade e privacidade; proteção contra agressor; informação sobre a tramitação processual, e garantia de presença em corte; acesso ao acusador público; restituição das coisas indevidamente tomadas ou apreendidas; informação sobre a condenação, a sentença, a prisão e a libertação do agressor.

Barros (2008) determina o conceito de sobrevitimização a partir não do sofrimento a que a vítima é submetida no inquérito e/ou no processo penal, mas a partir de um critério objetivo, compreendido como desrespeito aos direitos e garantias das vítimas no processo penal e como desrespeito aos seus direitos fundamentais. Um parâmetro importante é dado pela Declaração de Princípios Básicos de Justiça das Vítimas de Delito, que está dividida em quatro garantias: acesso à justiça e tratamento justo, ressarcimento, indenização e assistência social.

A vitimização terciária ocorre no âmbito do controle social, no desamparo da assistência social que se produz no reencontro com seus grupos de relação (família, escola, trabalho, igreja, no convívio social) e os organismos 
gerais de ajuda.

Além dos três conceitos acima, encontramos ainda o de autovitimização secundária fornecido pela Psicologia Jurídica, em que, segundo Trindade (2007), a vítima se culpa pelo evento criminoso, passando a recriminar-se pelo que aconteceu, procurando encontrar motivos para explicar o fato, supondo-se corresponsável pelo evento, o que lhe poderá causar sérios problemas de ordem psicológica.

Cabe destacar que a busca por direitos e garantias da vítima não significa a redução de direitos e garantias do acusado, nem colocar a vítima com direitos correlatos, mas contrapostos ao acusado, o que não se coaduna com o Estado Democrático de Direito.

Segundo Molina (1992), a vítima quer um modelo em que haja um diálogo com o sistema de justiça e segurança, e sua voz possa ser ouvida. Ainda, pretende que tal sistema seja resolutivo do conflito, o que, na perspectiva da vítima, deve incluir a reparação do dano.

\section{A mulher como vítima no processo penal brasileiro}

Os movimentos feministas contribuíram historicamente para a evolução dos direitos das mulheres, pressionando pela efetivação de políticas públicas e o pleno respeito à cidadania feminina. No Brasil, o advento da Lei 11.340, de 22 de agosto de 2006, que dispõe sobre a violência doméstica e familiar cometida contra a mulher, recolocou no cenário público o debate acerca das relações entre o direito e as desigualdades de gênero, ao identificar a mulher em situação de violência enquanto sujeito merecedor de atenção especial, sendo previstas medidas protetivas e toda uma rede de atendimento voltada as suas especificidades.

Esta Lei, conhecida como "Lei Maria da Penha", incorpora ao ordenamento jurídico nacional a categoria gênero, dispondo em seu artigo $5^{\circ}$ que configura violência doméstica e familiar contra a mulher qualquer ação ou

9 Seu nome foi dado em homenagem a uma farmacêutica brasileira que sofreu por duas vezes tentativas de homicídio, esperando por 20 anos uma decisão definitiva. Sem um processo justo num tempo razoável, acionou a Comissão Interamericana de Direitos Humanos que responsabilizou o Brasil por negligência e omissão em relação à violência doméstica cometida contra a mulher. 
omissão baseada no gênero que lhe cause morte, lesão, sofrimento físico, sexual ou psicológico e dano moral ou patrimonial, no âmbito da unidade doméstica, da família ou em qualquer relação íntima de afeto. Não disciplina, portanto, o tratamento de qualquer conduta lesiva contra uma mulher, mas é necessário que esta conduta seja baseada no gênero, conforme os próprios instrumentos internacionais passam a abordar a questão.

O uso desta categoria, contudo, trouxe certo estranhamento àqueles que se debruçaram sobre a interpretação e sobre a aplicação da nova Lei, por ser uma categoria nova dentro do ordenamento jurídico brasileiro, teorizada tradicionalmente por outras áreas de conhecimento, como a Antropologia, a Sociologia e a Psicologia.

Desde os anos 80 , há uma referência crescente a gênero na literatura especializada. De uma expressão pouco usual, ela se tornou quase frequente, sendo que diversas tramas teóricas foram sendo articuladas nesse conceito. Isto permite que o mesmo adquira certa instabilidade (já que sempre envolve um terreno contestado, não fixo), quanto um fator de vitalidade, que estimula e incita a um constante questionamento e autocrítica.

De acordo com Saffioti (2004), o primeiro estudioso a mencionar e a conceituar gênero foi Robert Stoller, em $1968^{10}$. Tais estudos carregavam marcas da militância feminista, que contribuíram para que emergisse nas ciências humanas a preocupação em se denunciar o processo de opressão que subordinava as mulheres a estereótipos e justificava desigualdades sociais sofridas milenarmente. No Brasil tal conceito irá se alastrar rapidamente nos anos 90, a partir da circulação do artigo da historiadora Joan Scott $(1989)^{11}$.

Esta autora ainda hoje é referência para análises em torno das relações de gêneros (entre homens e mulheres). Para ela, o conceito de gênero tem duas partes e várias subpartes, ligadas umas às outras. Na primeira parte, gênero "é um elemento constitutivo das relações sociais baseadas nas diferenças que distinguem os sexos"; na segunda parte, o gênero "é uma forma

10 A rigor, embora não tenha formulado o conceito de gênero, Simone de Beauvoir (1980) formulou os fundamentos do conceito de gênero, na sua famosa frase: "Não se nasce mulher, torna-se mulher".

11 SCOTT, Joan. Gênero: uma categoria útil para análise histórica. New York: Columbia University Press, 1989. (mimeo). 
primária de relações significantes de poder". As subpartes estão dispersas, presentes nos símbolos e nas representações culturais; nas normas e doutrinas; nas instituições e organizações sociais; nas identidades subjetivas.

Sob essa perspectiva teórica, gênero é, portanto, mais do que uma palavra: é uma ferramenta de análise que, aplicada a um dado objeto, resulta em uma forma específica de abordá-lo. Há muitas outras formas de compreender o gênero, contudo, é necessário termos como referenciais análises que rompam com as construções hegemônicas, permitindo identificar a parcialidade do sujeito, sem categorias estáveis e fechadas, que não pressupõem possibilidades de mudança na organização social.

O gênero, assim, é um conceito-chave nas ciências sociais que se refere à construção social do sexo, distinguindo a dimensão biológica da social. Neste raciocínio, há a distinção entre os sexos na espécie humana, mas há também a qualidade de ser homem e ser mulher, que é construída pela cultura, relacionalmente. Constitui-se, assim, em uma categoria de análise que afirma o caráter social e relacional para as diversas construções do masculino e feminino ao longo da História, nos diversos contextos existentes.

Importante considerar a construção dos gêneros como fundamentalmente ligada a um determinado processo social e histórico, ao envolver, de fato, os corpos dos sujeitos quando se inscrevem determinados gestos, posturas, disposições ou marcas. Gênero como constitutivo das relações sociais tem trazido valiosas contribuições, principalmente porque nos permite pensar não apenas a relação entre os gêneros: entre homens e mulheres, entre homens e entre mulheres, mas refletir sobre a própria construção cultural e social da noção de "homem" e de "mulher", carregada de historicidade nas suas relações, ao abordarmos gênero como uma construção social, um conceito plural, que invariavelmente levaria a diversas concepções de masculino e feminino, relacionais e não antagônicas entre si e, fundamentalmente, historicamente determinadas. Os estudos de gênero possibilitaram, em primeira mão, que se problematizasse a determinação biológica da "condição feminina".

Esta forma de instrumentalizar o conceito de gênero como ferramenta teórica vai para além de seu sentido como atributo de "papéis" masculinos e femininos de uma determinada realidade social. O gênero é constituído 
e instituído pelas múltiplas instâncias e relações sociais, pelas instituições, pelas formas de organização social e discursos que também o instituem em um processo dinâmico e relacional.

Ao pensarmos a inter-relação entre gênero e Direito ao longo da História, percebemos que o Direito tem contribuído, significativamente, para uma definição do "masculino" e do "feminino" que alimentam as desigualdades de gênero. Na realidade, não há como pensar o Direito desconectado da sociedade a que serve. Sociedade esta marcada por relações assimétricas de poder entre os gêneros.

O Sistema de Justiça Criminal deixa muito patente a relação entre o Direito e as desigualdades de gênero. Segundo Andrade (2011), porque o sistema de justiça criminal é parte de toda a mecânica de controle social ${ }^{12}$, que está enraizada nas estruturas sociais. Mais do que se preocupar com os sujeitos envolvidos, ele é constitutivo e reprodutor de assimetrias engendrando e alimentando estereótipos, preconceitos, discriminações e hierarquias, até porque suas normas e sua forma de execução foram estruturadas a partir de uma perspectiva masculina.

Como mecanismo público de controle dirige-se primordialmente aos operadores de papéis na esfera pública da produção material, no caso aos homens. Às mulheres, historicamente foi destinada a esfera privada, espaço da privação de todos os direitos que lhes facultariam se tornarem visíveis, alcançar um espaço na comunidade. Esta delimitação público x privado é, para Almeida (1998, p. 111), "uma construção ideológica, que encobre e perpetua áreas refratárias ao olhar público e à elaboração de determinadas políticas públicas, que não interessam ao modelo hegemônico de sociedade".

O Sistema de Justiça Criminal, ao se estabelecer enquanto um mecanismo público de controle social da esfera pública, constitui-se como um mecanismo masculino de controle de condutas masculinas, em regra daqueles que assumem na sociedade a figura de "sujeitos perigosos". Os presídios terminam assim lotados por homens jovens, negros, pobres, de-

12 Por controle social designam-se, em sentido lato, as formas com que a sociedade responde, informal ou formalmente, difusa ou institucionalmente, a comportamentos e a pessoas que contempla como desviantes, problemáticos, ameaçantes ou indesejáveis, de uma forma ou de outra e, nesta reação, demarca (seleciona, classifica, estigmatiza) o próprio desvio e a criminalidade como uma forma específica dele (ANDRADE, 2006). 
sempregados.

Segundo Buglione (2007), a criminalidade feminina no Código Penal Brasileiro sempre se limitou ao que se pode chamar de "delitos de gênero", como infanticídio (art. $123 \mathrm{CP}$ ), aborto (art. $124 \mathrm{CP}$ ), homicídios passionais (art. $121 \mathrm{CP}$ ), exposição ou abandono de recém-nascido para ocultar desonra própria (art. $134 \mathrm{CP}$ ), furto (art. $155 \mathrm{CP}$ ), além da ideia de que a conduta criminosa estivesse estritamente relacionada com os delitos dos companheiros e maridos.

Em realidade, as mulheres adentram no sistema de justiça criminal essencialmente na figura de vítimas, principalmente ao se tratar do controle sobre sua sexualidade ${ }^{13}$, ou seja, na "preservação da virgindade e zelo pela reputação da mulher". Aqui, todavia, também o sistema faz suas seleções binárias, existindo as vítimas honestas ou não, como as prostitutas. Na criminalização sexual o sistema criminal segue, com grande contundência, a lógica da seletividade, acendendo seus holofotes sobre as pessoas (autor e vítima) envolvidas, antes que sobre o fato-crime cometido, de acordo com estereótipos de violentadores e vítimas.

Nos Tribunais talvez seja onde mais radicalmente se percebem os conflitos de gênero. As decisões judiciais expressam toda essa conflituosidade, possuem uma dinâmica própria, de movimentos contraditórios, e por isso compõem um universo heterogêneo, permeado de avanços e retrocessos. Essas decisões devem ser entendidas não apenas dentro da lógica interna da justiça, mas dentro da lógica da sociedade e das formas que apresenta para a solução desses conflitos. O sistema de justiça criminal quando se volta aos conflitos de gênero expressa o imaginário de casamento, de família e de papéis sociais presentes na sociedade.

O agressor que é um bom pai de família raramente é punido. Por outro lado, a mulher que exerce sua sexualidade é tratada de forma desdenhosa e seu testemunho acaba sendo desconsiderado.

Não se pode esquecer também do surgimento da excludente de cri-

13 O controle da sexualidade feminina, através de seu aprisionamento na função reprodutora, historicamente constitui, ao lado da centralidade do trabalho doméstico, um dos dois grandes eixos pelos quais se concretizam as relações específicas de dominação, controle que encontra na lei penal vigente largo campo de atuação. 
minalidade que nunca figurou na lei: a legítima defesa da honra, que deu ensejo à absolvição de um sem-número de maridos e ainda hoje é utilizada.

Em realidade, existe uma lógica anterior aos fatos, que é a forma como a Justiça (na voz de seus representantes) constrói um modelo ideal de homem e de mulher. Muitas vezes está em jogo num julgamento a forma como os acusados e as vítimas se travestem de modelos repletos de ambiguidades e contradições que refletem os preconceitos de que estão revestidos os próprios juízes.

Os delitos sexuais no Brasil sofreram recente modificação ${ }^{14}$ que os considera não mais "crimes contra os costumes", mas sim crimes contra a dignidade sexual. A objetividade jurídica protegida é a integridade sexual da mulher e não mais a moral social, como se a parte ofendida fosse o ente social, e não a mulher. Nos séculos XIX e XX, muitos bens jurídicos acabaram cindidos, restando à esfera sexual muito mais um verniz subjetivo do que qualquer outra coisa.

O pudor, a moral, a honestidade e os costumes, sedimentados pelo peso da religião, culminaram no que se poderia ter por liberdade sexual. Desta feita, ainda hoje percebemos no julgamento destes crimes, um quadro que muito mais do que elucidar determinantes contextuais e sociais da quebra das normas, representa a defesa de um sistema de valores. O crime, como uma quebra de determinada regra jurídica, servirá ao mesmo tempo como pretexto para o escrutínio da adequação ou não do acusado e da vítima a outras normas de convívio social e ao seu reforço ou enfraquecimento.

As reformas nesses crimes começaram em 2005, através da Lei 11.106, extinguindo de nosso ordenamento colocações relativas à honestidade da mulher (extremamente ligada à moral sexual) ou mesmo quanto à incriminação do adultério. Tal reforma segue a reformulação de conceitos penais sexuais que a Europa implementou desde a década de 1960.

Tais reformas ainda resistem, contudo, diante do conservadorismo da sociedade. Prova disso é o que ocorreu com o estupro, que nos termos do Código Penal era considerado um crime de ação penal privada, somente 
sendo o homem processado com a vontade da mulher. O que ocorria na prática era deixar sob única responsabilidade da mulher o desenvolvimento do processo. Esta arcava com o ônus de acompanhar o processo desde a fase policial, tendo que contratar um/a advogado/advogada, sofrendo pressões por parte do agressor, revivendo constantemente a agressão sofrida e muitas vezes abandonando o prosseguimento do feito.

A Lei 8.072, de 25 de setembro de 1990, coloca o estupro no rol dos chamados "crimes hediondos", aumentando a rigidez e severidade da resposta punitiva. O Supremo Tribunal Federal (STF), contudo, redimensionou a interpretação que havia dado ao crime de estupro, deixando de considerá-lo como crime hediondo nos casos que não envolviam lesão corporal de natureza grave ou morte. Tal interpretação possibilitava a flexibilização da aplicação do regime de pena para as pessoas condenadas pelas suas práticas, quando houvesse "apenas" a violência sexual. Graças a dissidências nesse entendimento e a críticas dos movimentos de mulheres, o Supremo Tribunal Federal mudou, em 17 de dezembro de 2001, seu entendimento para considerar a forma simples como hedionda ${ }^{15}$. O STF também editou a Súmula 608, que considera o estupro crime de ação penal pública incondicionada, colocando a punição como uma obrigação do Estado.

Ocorre que a Lei 12.015 altera o Código Penal, tornando o estupro crime de ação penal pública condicionada a representação, em que o prosseguimento da ação somente ocorre com a iniciativa da vítima, ignorando todo o avanço trazido pela Súmula 608 e trazendo grande prejuízo para os processos que tramitavam ${ }^{16}$.

Importante destacar que todo esse sistema em torno do Direito Penal no âmbito dos crimes sexuais sustenta-se, conforme disciplina Baratta (1978), sob uma ideologia extremamente sedutora e com um fortíssimo apelo legitimador (da proteção, da evitação, da solução) como se à edição de cada lei penal, sentença, ou cumprimento de pena, fosse mecanicamente sendo

15 A nova jurisprudência ficou consolidada pelo julgamento do Habeas Corpus (HC 81288), tendo sido indeferidoo pedido de redução de pena porum paicondenado pormanter relações com filhas menores de idade durante um período prolongado.

16 Esta modificação foi aplicada mesmo aos crimes ocorridos antes da vigência da Lei por beneficiar o agressor, levando a situações extremas em que processos poderiam ser extintos quando a vítima estivesse morta e não tivesse ninguém que a representasse. 
cumprido um pacto mudo que opera o traslado da barbárie ao paraíso.

Contudo, é necessário ter um olhar mais acurado da própria sociedade brasileira e da sua absoluta carência de direitos e de cidadania. Com a Lei Maria da Penha, percebemos que a simples mudança no ordenamento jurídico não representa um real comprometimento com a concretude da cidadania feminina manifesta dos/as agentes do Direito.

Ainda hoje temos inúmeras dificuldades para a efetiva aplicação da Lei. Faltam varas, promotorias e delegacias especializadas; profissionais do Direito para atuar nas estruturas criadas; capacitação para os/as servidores/ as; além de mais sintonia na interpretação da lei, pois cada juiz/a que ocupa uma das varas pensa diferentemente sobre questões fundamentais e altera os procedimentos existentes.

Toda essa resistência na aplicação de uma lei que tem enfrentado uma realidade tão gritante configura um processo de sobrevitimização. As muIheres em situação de violência já se encontram diante de diversas barreiras sociais difíceis de serem transpostas, como a pressão de familiares, dos amigos, (em alguns casos) da Igreja ao invocarem a "preservação da família". E, sobretudo, as ameaças de novas agressões e de morte a que elas são submetidas. Em grande parte dos casos há o medo por parte das mulheres com a possibilidade de prisão do ex-companheiro e o rompimento de laços familiares ou a perda do padrão de vida. Quando finalmente decidem denunciar, defrontam-se com um processo moroso, técnico e frio aos seus anseios, com agentes sem capacitação adequada para entender seu problema e lhe dar as devidas orientações.

As mulheres em situação de violência sentem dificuldade de compreender os meandros da Lei porque não são colocadas como protagonistas dos debates acerca das ações que protagonizam, e se veem reféns das imposições do marido e familiares e, em muitos casos, dos agentes do direito que atuam em seus processos. Um dos principais desafios é justamente como transformar o direito em um valor. Reconhecer a violência para nomeá-la, tipificá-la ao atribuir-lhe significados que dialoguem com o social e com o contexto individual em que foi impetrada para sua real efetividade é um dos principais desafios a serem enfrentados. 


\section{Por uma visão procedimentalista e discursiva do direito}

No Estado Democrático de Direito devemos ter a compreensão de um direito que seja participativo, em que a sociedade civil exerça importante papel controlador e conformador do Estado, pluralista, respeitando os diversos matizes sociais, na busca da implantação de direitos. Não importa ter direito se não há garantias mínimas de que a atuação estatal não atingirá os indivíduos em seus direitos. A redefinição da esfera pública e privada, num modelo revisável e argumentativo, constitui um dos elementos definidores do Estado Democrático de Direito.

Preciosos neste momento são os ensinamentos da Teoria discursiva de Habermas. O autor retoma o pensamento de Kant quanto à análise da legitimidade do direito. Assim, deve ser possível obedecer as normas do direito, não porque sejam coercitivas, senão porque são legítimas. A validade de uma norma jurídica indica que o poder estatal garante simultaneamente a legítima produção do direito e a fática imposição do mesmo.

Para que o direito seja legítimo são necessárias duas importantes expressões como elementos justificadores: soberania popular e direitos fundamentais. A soberania popular estabelece um procedimento e fundamenta a suposição de resultados legítimos. Este princípio se expressa nos direitos de comunicação e participação. Por outro lado, os direitos humanos clássicos, que garantem aos cidadãos de uma sociedade a vida e a liberdade privada, fundamentam por si mesmos um domínio legítimo das leis. Sobre estes pontos de vista, o direito produzido deve ser legitimado como um meio para assegurar de forma harmônica a autonomia dos indivíduos, tanto em âmbito privado como em sua dimensão de cidadãos.

Desta feita, os direitos fundamentais, os quais os cidadãos se outorgam reciprocamente como sujeitos de direitos, serão considerados legítimos quando todos os possíveis afetados puderem estar de acordo como participantes em um discurso racional, discurso este que dá origem a um resultado legítimo, haja vista que pressupõe um procedimento democrático comunicativo institucionalizado juridicamente.

Habermas (1997) estrutura sua teoria discursiva por meio da interligação que faz entre princípio democrático e forma jurídica, a partir do reco- 
nhecimento das duas bases: soberania popular - espectro da autonomia pública - e direitos fundamentais - espectro da autonomia privada.

Segundo o autor, há um processo circular de formação democrática da opinião e da vontade, de modo que depende concomitantemente de realização das liberdades subjetivas, que permitem a participação do cidadão no procedimento de tomada de decisão próprio da soberania popular, necessária para o estabelecimento das liberdades subjetivas. Autonomia privada e pública se pressupõem mutuamente, são cooriginárias, sendo que Habermas dá muita atenção aos processos de comunicação nas quais essa autonomia pode se manifestar e comprovar-se.

Segundo o pensamento habermasiano, para que a convivência seja regulada pelo direito positivo, é preciso que os sujeitos de direito sejam compreendidos, ao mesmo tempo, como destinatários e autores da norma. Habermas acredita na superação do Estado social com o paradigma procedimentalista do Estado Democrático de Direito, segundo o qual os sujeitos de direitos adquirem importantes papéis como agentes formadores e conformadores da sociedade, a partir do exercício de sua autonomia privada e pública.

Para efetivação da autonomia pública, ou autonomia cidadã, é necessária a participação na formação da opinião e da vontade, é imprescindível a atuação dos sujeitos de direito, mediante a opinião pública, como agente controlador da atuação estatal, mas principalmente, mediante sua participação no processo decisório, na atuação legislativa ou mesmo no âmbito judiciário.

As bases atuais do movimento vitimológico repousam no paradigma do Estado Democrático de Direito, particularmente entre a realização da autonomia pública e privada dos indivíduos sujeitos de direito. $\mathrm{O}$ estabelecimento de direitos fundamentais depende da participação dos afetados no processo de discussão e formação de opinião e vontade, que somente pode ser garantido se a autonomia pública que lhe complementa puder ser exercida. Ambas as autonomias devem ser garantidas para assegurar o processo democrático.

O Estado Democrático de Direito implica uma pretensão de aceitabilidade do Direito por todos, diferentemente do Estado do Bem-Estar Social, 
em que a expansão do Estado, no sentido de buscar um tratamento jurídico de qualquer situação que visasse o "fim social", acabou criando "guetos jurídicos" sem que houvesse uma efetiva participação dos afetados pelas normas criadas.

Desta feita, no Estado Democrático de Direito o Estado, a partir do seu aparelho jurisdicional repressor, possui legitimidade para solucionar o conflito, mas não pode fazê-lo excluindo e neutralizando um dos principais protagonistas: a vítima.

Essa preocupação com a vítima está proclamada na Constituição Brasileira de 1988, que em seu art. $1^{\circ}$, III, dispõe que um dos fundamentos do Estado Democrático de Direito é a dignidade da pessoa humana. Além disso, previsto o direito constitucional ao processo, no art. $5^{\circ} \mathrm{XXXVI}$, da Constituição, não há espaço para qualquer entendimento de que a vítima não possa participar do processo legal como sujeito de direito, em virtude da garantia do devido processo legal, da proteção jurídica e do contraditório. Os supostos interesses meramente vingativos da vítima seriam inviabilizados pela própria estrutura procedimental do processo a partir das garantias relacionadas ao devido processo legal, principalmente as relacionadas à proteção do acusado como sujeito de direito.

Um primeiro ponto a ser destacado quanto à participação da vítima é a necessidade de seu consentimento, entendendo-se como obrigação do Estado respeitar e fomentar a liberdade de seus cidadãos. Em verdade, o crime representa um conflito de natureza dialógica, das partes e não de terceiros.

Nesse contexto, é relevante ressaltar a importância da Teoria da relação jurídica para a Teoria do processo e para o processo penal em especial, pois foi com a relação jurídica processual que o acusado passou a ser sujeito de direitos, não mais um mero objeto processual. Segundo Barros (2008), contudo, no Estado Democrático de Direito não é possível compreender o processo como relação jurídica, na qual um sujeito tem poder sobre a conduta de outrem, ou seja, as partes se colocam uma em frente à outra em posição de sujeição e supraordenação.

Se analisarmos o conceito de direito subjetivo, enquanto poder de um sob a conduta de outrem, ele não pode ser aplicado no processo penal, pois 
não há como determinar o vínculo de subordinação entre a conduta do autor frente ao réu ou mesmo do réu perante o juiz e deste perante o autor.

A noção que mais se adapta ao paradigma do Estado Democrático de Direito é a Teoria do processo como procedimento em contraditório, de Fazzalari (1992). Um procedimento realizado em contraditório, mediante a participação dos atingidos pelo provimento e que se encontram em situação contrária diante do conflito a ser resolvido, em simétrica paridade de armas. O processo penal não precisa ser justificado pela expropriação do conflito, mas pela construção participada dos afetados pelo provimento jurisdicional.

Cabe aqui ressaltar a distinção feita por Fazzalari (1992) entre processo e procedimento. Para o autor, a distinção deve ser feita por um critério lógico, dentro do próprio sistema jurídico que os disciplina. E o sistema normativo revela que há entre eles uma relação de inclusão, sendo o processo uma espécie do gênero procedimento, e, que pode ser dele separado por uma diferença específica, uma propriedade que possui e que o torna distinto. Esta é a presença no processo do contraditório. O processo é um procedimento, mas não qualquer; é aquele de que participam interessados no ato final, de caráter imperativo, por ele preparado, mas não apenas participam; participam de uma forma especial, em contraditório entre eles, porque seus interesses em relação ao ato final são opostos.

Em Leal (2008) somos alertados, porém, para o fato de que não basta reconhecer que o processo é um procedimento técnico-estrutural em contraditório entre as partes, porque o simples dizer que o processo é um procedimento em contraditório não emprestaria necessária e juridicamente ao procedimento o predicado principiológico, balizador e definidor do contraditório. Importa afirmar que na verdade não há processo, nos procedimentos, quando o processo não estiver, antes, institucionalmente definido e constitucionalizado pelos fundamentos normativos do contraditório, ampla defesa, direito ao advogado e isonomia, aos quais deve ser acrescentado ainda o princípio do devido processo legal. Conclui o autor, dizendo que sem esta institucionalização de fundo constitucional, ainda que o procedimento respeite o contraditório, não há que se falar na existência de processo.

Esta teoria vem sendo denominada "teoria neo-institucionalista do processo" e se baseia na ideia de que o Estado na pós-modernidade não é o 
todo do ordenamento jurídico, mas está no ordenamento jurídico em situação isonômica com outras instituições e com estas se articula de modo interdependente e num regime jurídico de subsidiariedade recíproca. $\mathrm{Na}$ condição de direito-garantia, o acesso à justiça e ao processo com todos os seus predicados é cláusula pétrea da Constituição brasileira ( $\S 4^{\circ} \mathrm{do}$ seu art. 60), o que reforça a sua característica institucional, vez que inatacável pela via legiferante, só podendo ser inobservado no caso de um retrocesso à política das baionetas.

Segundo Marinoni (2011), a participação das partes no procedimento, embora importante, é insuficiente para garantir a legitimidade da jurisdição. A parte, além de ter o direito de participar do processo, possui o direito ao procedimento adequado à tutela do direito material ${ }^{17}$. Para a legitimidade da jurisdição, segundo o autor, se faz ainda necessária a legitimidade do procedimento diante dos direitos fundamentais - não apenas processuais, como o direito ao contraditório -, mas também materiais.

A Vitimologia, nascida sob o paradigma do Estado Democrático de Direito, não busca o reconhecimento da vítima com a exclusão ou, sequer, possível redução dos direitos do acusado no processo penal, o que está explícito inclusive na Declaração da ONU. Não busca também o endurecimento penal ou a criação de novos tipos penais, mas a retomada do diálogo entre vítima e agente e a efetivação dos direitos dela, inclusive o de reparação do dano.

\section{Considerações finais}

Após todo o esquecimento histórico, a vitimologia trouxe importantes contribuições para o reconhecimento do ofendido como sujeito de direitos, como parte integrante necessária do procedimento criminal, que possui interesse direto no resultado do processo e cuja expectativa de reparação não reside apenas na apenação vingativa do acusado pelo Estado-juiz.

17 Esse direito incide sobre o legislador, obrigando-o a instituir procedimentos idôneos, assim como sobre o juiz, especialmente em razão das normas processuais abertas, que dão à parte o poder de estruturar o procedimento segundo as necessidades do direito material e do caso concreto. 
Faz-se mister instituir um sistema que não gere a sobrevitimização de quem já se encontra em estado fragilizado, rompendo-se com todas as preleções contidas na Constituição Federal, que erige uma gama de direitos e garantias fundamentais a ser assegurada pelo Estado democrático a todos os cidadãos. No caso das mulheres, isso só torna mais patente na medida em que historicamente foram alijadas de sua autonomia privada e pública, sofrendo todas tramas de gênero no processo penal, ao serem questionadas em seu papel de "boa vítima" e de "boa mulher", sem ter as garantias necessárias para o rompimento de sua condição.

Mais do que mudar a lei ou propor soluções de lege ferenda, significa começar pela garantia de uma interpretação constitucionalmente adequada, e pela eficácia imediata das garantias constitucionais como previstas no artigo $5^{\circ}, \S 1^{\circ}$, da Constituição Brasileira. A vítima é sujeito de direito, devendo ser compreendida como parte contraditora, pois é afetada pelo provimento jurisdicional em razão de seus direitos constitucionalmente garantidos, seja o direito à reparação do dano decorrente do ilícito penal, seja em virtude de suas garantias processuais advindas do princípio do devido processo legal, que determina a reconstrução fática do delito.

Ademais, a superação de um modelo penal estritamente retributivo, com vistas à utilização de métodos de recomposição dos danos, além de proporcionar efetiva reparação à vítima também agracia o acusado que se vê distante da face vingativa do jus puniendi.

A melhor justificação filosófica para a superação deste modelo processual baseado na expropriação do conflito é a compreensão procedimentalista do Direito, que garante a um só tempo a autonomia pública e privada dos cidadãos em sua cooriginalidade e equiprimordialidade.

No Estado Democrático de Direito, o cidadão é compreendido como autor e destinatário do direito, operando-se uma mudança com a participação do afetado no processo de construção e reconstrução comunicativa de seus direitos. Para tanto o processo penal deve ser destituído de uma compreensão do processo como relação jurídica, para compreendê-lo como procedimento realizado em contraditório pelos sujeitos afetados pelo provimento jurisdicional. Isso garante que a decisão será construída pelo discurso argumentativo empreendido pelas partes e não pela atuação isolada do juiz. 
No paradigma do Estado Democrático de Direito exige-se a participação da mulher em situação de violência, mediante suas autonomias públicas e privadas, tanto na formação da opinião e vontade fomentadas a partir da discussão de pautas públicas relacionadas à segurança pública ou às diversas formas de violência, quanto por meio de soluções consensuais, por meio do processo penal, de modo que seja dada atenção as suas demandas.

\section{Referências}

ALMEIDA, Suely Souza de. Femicídio: algemas (in)visíveis do públicoprivado. Rio de Janeiro: Revinter, 1998.

ANDRADE, Vera Regina Pereira de. A soberania patriarcal: o sistema de justiça criminal no tratamento da violência sexual contra a mulher. Revista Eletrônica de Ciências Jurídicas, São Luiz, v. 3, 2006. Disponível em: http://www2.mp.ma.gov.br/ampem/artigos/artigos2006/A_soberania_ patriarcal_artigo_Vera_Andrade.pdf. Acesso em: 14 maio 2011.

BARATTA, Alessandro. Criminologia crítica e política penal alternativa. Revista de Direito Penal. Rio de Janeiro, n. 23, p. 7-21, jul/dez. 1978.

BARROS, Flaviane de Magalhães. A Participação da Vítima no Processo Penal. Rio de Janeiro: Lumen Juris, 2008.

CHAMON JÚNIOR, Lúcio. Imputação e risco no direito penal lineamentos de uma dogmática em termo da teoria do discurso. Dissertação de mestrado. Belo Horizonte: Universidade Federal de Minas Gerais, 2003.

DIAS, Jorge de Figueiredo; ANDRADE, Manoel Costa. Criminologia. Coimbra: Coimbra Editora, 1997.

FAZZALARI, Elio. Instituzioni di diritto processuale. Padova: Cedam, 1992.

FERNANDES, Antonio Scarance. O papel da vítima no processo criminal. São Paulo: Malheiros, 1995.

HABERMAS, Jurgen. Direito e Democracia: Entre facticidade e validade. Rio de Janeiro: Tempo, 1997. v. I e II.

MARINONI, Luiz Guilherme. Da teoria da relação jurídica processual ao processo civil do estado constitucional. Disponível em: http://www. 
abdpc.org.br/abdpc/artigos/Luiz\%20G\%20Marinoni(8)\%20-\%20formatado. pdf. Acesso em: 08 maio 2011.

MOLINA, Antônio García-Pablos. Criminologia: uma introdução a seus fundamentos teóricos. São Paulo: Revista dos Tribunais, 1992.

LEAL, Rosemiro Pereira. Teoria Geral do Processo: Primeiros Estudos 7. ed. Rio de Janeiro: Forense, 2008.

SAFFIOTI, Heleieth I. B. Gênero, patriarcado, violência. São Paulo: Perseu Abramo, 2004.

TRINDADE, Jorge. Manual de Psicologia Jurídica para Operadores do Direito. 2. ed. Porto Alegre: Livraria do Advogado, 2007.

ZEDNER, Lucia. Victims. Capítulo 18 de The Oxford Handbook of Criminology. Maguire, Mike; Rod Morgan e Robert Reiner. Oxford: OUP. 2nd. Ed. 1997 p. 578. 